\title{
自由縁特異応力の減少に係わる知的形状設計についで
}

\author{
村田雅 人*1, 高原渉*1

\section{Intelligent Shape Design for Reduction of Free-Edge Singular Stress}

\author{
Masato MURATA and Wataru TAKAHARA
}

\begin{abstract}
Shape optimization is applied to dissimilar material joints to decrease free-edge singular stress using a CAE system of finite element-based shape optimization programs. The optimum shape of a joint with an interlayer is similar to the case of that without an interlayer. It is revealed that the free-edge singular stress decreases in the optimum shape. Shape optimization is a useful method for designing dissimilar material joints from the point of view of decreasing singular stress.
\end{abstract}

Key Words: Optimum Design, Finite Element Method, Adhesive Joints, Singular Stress, Free Edge Shape, CAE, Dissimilar Material Joints

\begin{abstract}
1. 緒踏
買材接合体においては，その界面が自由縁と交わ る所にいわゆる自由縁心力特異性が生じ, 強度低下 の原因となってしまうことが知られている(1)。しか し，材料特性と接合部の形状によっては，この応力 特異性が消失することが指摘されており，接合部の 幾何形状を固定したときの材料特性の組み合わせや 逆に材料特性が与えられたときの接合部形状につい て, 応力特買性消失の条件という観点から議論され ている(1)(2)。接合部の形状設計を行う場合は，こう した特異性消失の条件を考虑に入れることが望まし いしかしながら，奏際の接合部には，中間首，接 着層が入ることも多く，こういった複雑な状沙にな ると, 理論解をもとにした形状設計は困難になると 考えられる。よって，接合部に中間層か入るなど複 雑な場合にも適用可能な設計手法が求められる，沉 用の数值解析手法である有限要素法を接合界面に応 用する場合には，界面端に生じる応力特異性をどう 扱うかといった問題がつきまとうい。しかし，有限 要素法を利用した接合体の形状最適化については， 中間層がない場合ではあるが既に報告があり，有限 要素法を組み合わせた形状最適化によって，忍力集 中を低減した継手設計の可能性が示唆されている (3).(4). 最近は，個人での使用が可能なエンジニアリ ングワークステーションやパーソナルコンピュータ
\end{abstract}

* 济稿受付 1996 年10月2811。

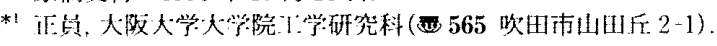

が著しく高性能化，低価格化しており，形状最適化 に関しても，CAE システムプログラムが既に市販さ れている。こうした CAEシステムは今後ますます充 央してくるものと思われる(5).(6). CAEによる形状最 適化では，応力特異性の問題はまだ十分に扱われて いない状況にあるといえるが，今後もし接合体に対 して，CAEシステムによる知的形状設計が可能にな れば，そのメリットは非常に大きいものがあると思 われる.

そこで本研究では，CAE システムを利用した接合 体の知的形状設計の可能性を探るため，自由粶特異 応力を有限要素法における要素の自動除去法により 減少させることを試み，得られる結果について検討 した。

\section{2. 解析手法およひモテル}

本解析に使用した CAE システムは，E.M.R.C. (Engineering Mechanics Research (oorporation)が 供給する最適化 FEMプログラムNISA/SHAPEであ る(7).(8).このプログラムは，構造解析には有限要素 法, 形状最適化には Lagrange 未定乗数法による最 適性規準法を利用している。図 1 にこのプログラム の流れ図を示す(9)。初期モデルに対し，まず有限要 素法により各要素の応力状態を求め, 変位または応 力の上限值を制䄪条件として，要素の有無そのもの を設計変数とし, 要素の除去により目的関数の体皘 もしくは重量を最小にしていく(7) (10).一般に要素除 去による方法では，そのプロセスの中で，本来の最 適形状解で残るべき要素まで取り去ってしまう可能 


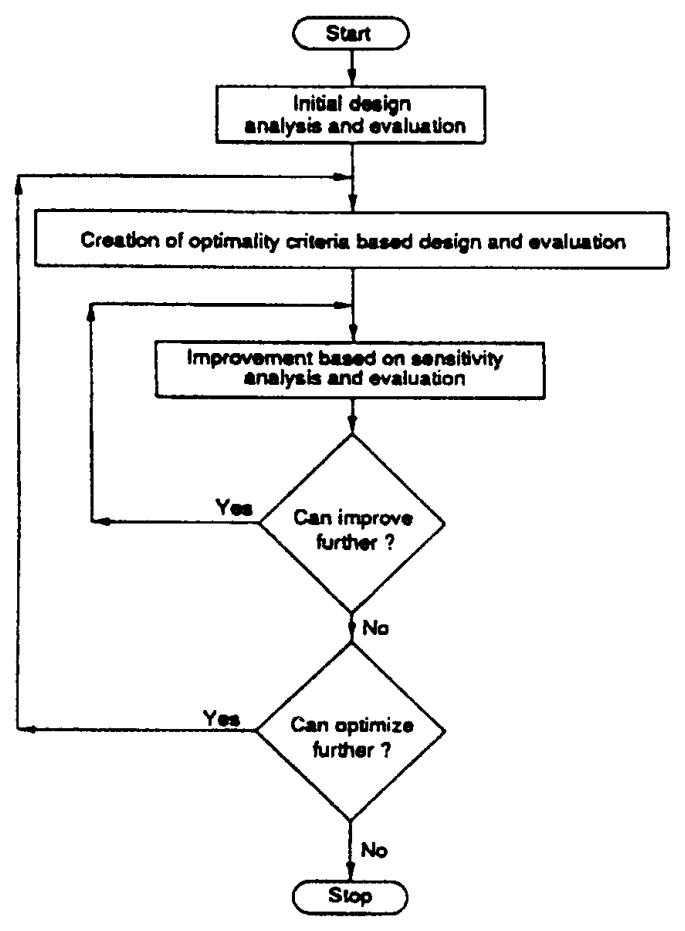

Fig. 1 Macro flowchart of the shape optimization algorithm(9).

性があるので，このプログラムでは，一旦除去した 要素を場合によっては回復させるプロセスも含んで いる，すなわち，まず，制約条件下でラグランジュ 乗数法により形状最適化がなされ，制約臨界状態に ある最適要素面積に関する情報を得る。しかし，そ れをそのまま実行すると形状変化に伴う応力状態の 変化のために，場合によっては最適化がうまくいか ない可能性がある。よって, 制粎臨界状態にある要 素は感度解析にかけられ, 要素回復により最大の効 果をあげる位置探索がなされ，その要素は復活させ る.こうして 1 ステップが終了し，もういちど最初 に戻って次のステップに移行していく(9). 本解析で は,このステップ数は 15 回を限度とすることにした. このプログラムではモデルの内部からの要素除去も 可能亡なっているが, ここでは，要素除去は境界部 のみを対象として行うこととした。なお，構造解析 はすべて弾性解析で行っている。

図 2 に, 本研究での解析の初期モデルの基本的形 状を示す.ここでは $\mathrm{Al}_{2} \mathrm{O}_{3}$ ・ Kovar 接合体を想定し， その間に中間酋 $\mathrm{Ag}$ が存在する接合体モデルも解析 の対象とした．ただし，図中 NB と記した部分は接 合されていないものとしている．荷重は引張荷重と して矢印をつけた部分に $40 \mathrm{~N}$ を負荷した. 用いた材 料定数については，ヤング率は Kovar が $156 \mathrm{GPa}$, $\mathrm{Al}_{2} \mathrm{O}_{3}$ は $294 \mathrm{GPa}, \mathrm{Ag}$ は 81GPa とした(11)。またポア

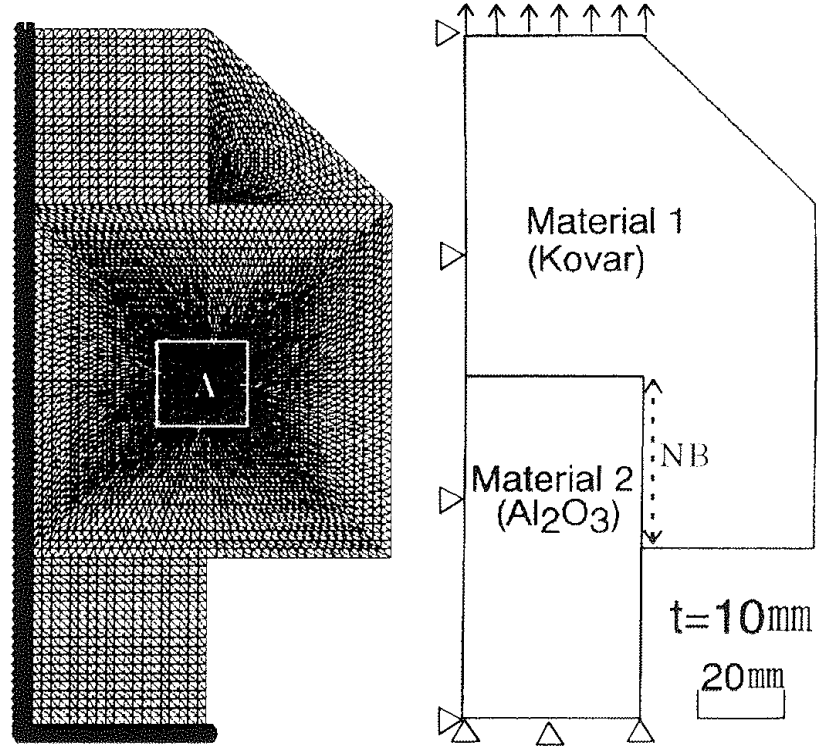

(a) no interlaver
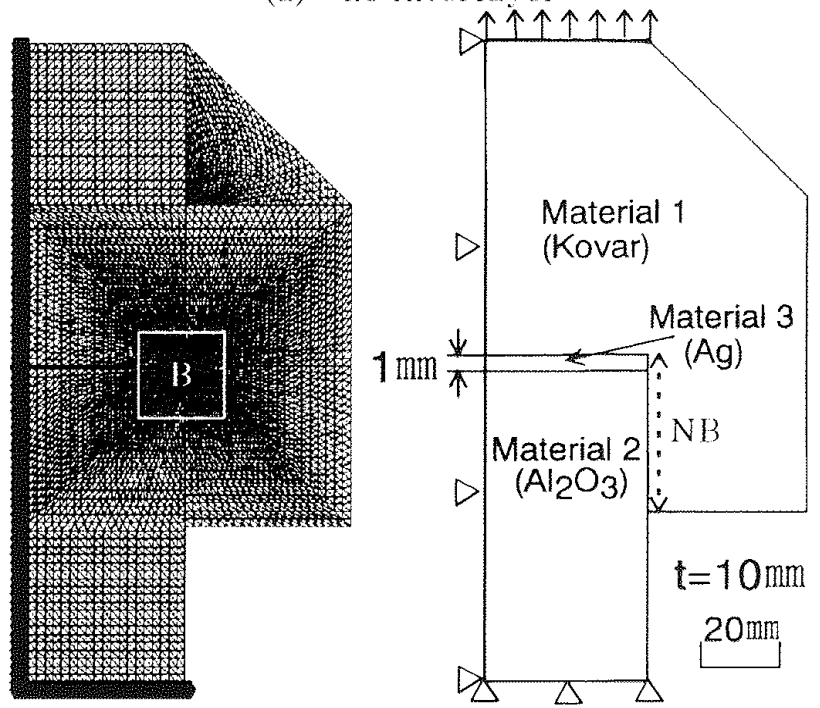

(b) with interlayer

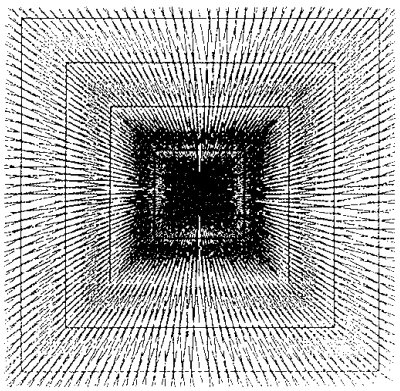

Detail of $\mathrm{A}$

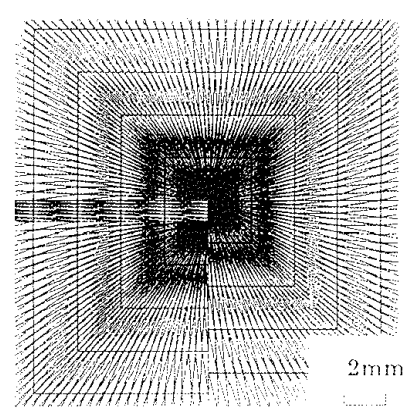

Detail of $\mathrm{B}$
(c)Details of FEM mesh

Fig.2 Finite element model of dissimilar material joints.

ソン比は，ここでは久保・大路の理論解(2)との比較 を容易にするために，どの材料も 0.3 であるとした。 弾性解析は，3 角形要素を使用した平面応力, 平面 ひずみ，軸対称モデルで行った。制約条件には相当 
応力 $\bar{\sigma}=\left[\frac{3}{2} \sigma^{\prime}{ }_{i j} \sigma_{i j}^{\prime}\right]^{1 / 2}$ を用い, 初期モデルの弾性解 析の結果得られる最大の相当応力值よりは大きいが それになるへく近いような值を選び，どの要素の相 当応力值もこの值を越えないという制約条件を与え た。なお、ここでは CAE システムを利用した接合体 の形状設計として, 要素の自動除去法により自由縁 特異応力を減少させることを試みているが，要素除 去は，Kovar からのみ行い，Kovar 中でも荷重負荷 部およびその近傍の領域からの除去は行わず，また， $\mathrm{Al}_{2} \mathrm{O}_{3}$ および $\mathrm{Ag}$ の部分からの除去も行わないものと した，そして，中間層のあるモデルにおける界面の 比較検討は, 材料 1 と中間層の界面について行い, 中間層と材料 2 の界面の方は考慮しないものとした。

\section{3. 解析結果および考察}

まず，中間層のない $\mathrm{Al}_{2} \mathrm{O}_{3} \cdot \mathrm{Kovar}$ 接合体につい て, 特異性が現れない幾何形状がどうなるかを，久 保・大路の方法(2)により求めてみる. 2 次元等方性弾 性体の異材モデルを考え, Kovar のヤング率, ポア ソン比をそれぞれ $\mathrm{E}_{1}, \nu{ }_{1}, \mathrm{Al}_{2} \mathrm{O}_{3}$ のヤング率, ポア ソン比をそれぞれ $\mathrm{E}_{2}, \nu_{2}$ として，図 3 のような接 合体を想定し，これに本解析における図 2 (a)の $\mathrm{A}$ 部 をあてはめて考えてみる. $\mathrm{Al}_{2} \mathrm{O}_{3}$ の部分では $\theta_{2}=$ $90^{\circ}$ となっているが,久保・大路によれば, $\theta_{2}=90^{\circ}$ の場合の自由縁特異性の消失条件について，

$2 \sin \theta_{1}\left(\theta_{1} \cos \theta_{1}-\sin \theta_{1}\right)(1-\alpha)(\alpha-4 \beta-1)$

$=\left[\sin \theta_{1} \cos \theta_{1}(1-\alpha)+2(1+\alpha)\right.$

$\left.+8 \sin ^{2} \theta_{1}\right](1+\alpha)$

が得られている(2)。ただし， $\alpha ， \beta$ は Dundersパラ メータで,

$$
\alpha=\left[\left(\begin{array}{ll}
\mu_{2} / \mu_{1}
\end{array}\right)\left(\chi_{1}+1\right)-\left(\begin{array}{l}
\left.\left.\chi_{2}+1\right)\right] /\left[\left(\mu_{2} / \mu_{1}\right.\right.
\end{array}\right)\left(\chi_{1}+1\right)\right.
$$$$
\left.+\left(\chi_{2}+1\right)\right]
$$

$\beta=\left[\left(\begin{array}{ll}\mu_{2} / \mu_{1}\end{array}\right)\left(\chi_{1}-1\right)-\left(\chi_{2}-1\right)\right] /\left[\left(\begin{array}{ll}\mu_{2} / \mu_{1}\end{array}\right)\left(\chi_{1}+1\right)\right.$

$$
\left.+\left(\chi_{2}+1\right)\right]
$$

であり, せん断弾性係数 $\mu_{i}$ は

$$
\mu_{\mathrm{i}}=\mathrm{E}_{\mathrm{i}} / 2\left(1+\nu_{\mathrm{i}}\right)
$$

であり, $\chi_{j}$ は

$$
\begin{aligned}
\chi_{j} & =3-4 \nu_{j} & & \text { (平面ひずみ) } \\
& =\left(3-\nu_{j}\right) /\left(1+\nu_{j}\right) & & \text { (平面応力) }
\end{aligned}
$$

である(1),(2).

これらの式(1)〜(5)に，材料定数を代入して $\theta_{1}$ を 求めると,

平面ひずみのとき， $\theta_{1}=118^{\circ}$

平面応力のとき, $\quad \theta_{1}=121^{\circ}$

となる。

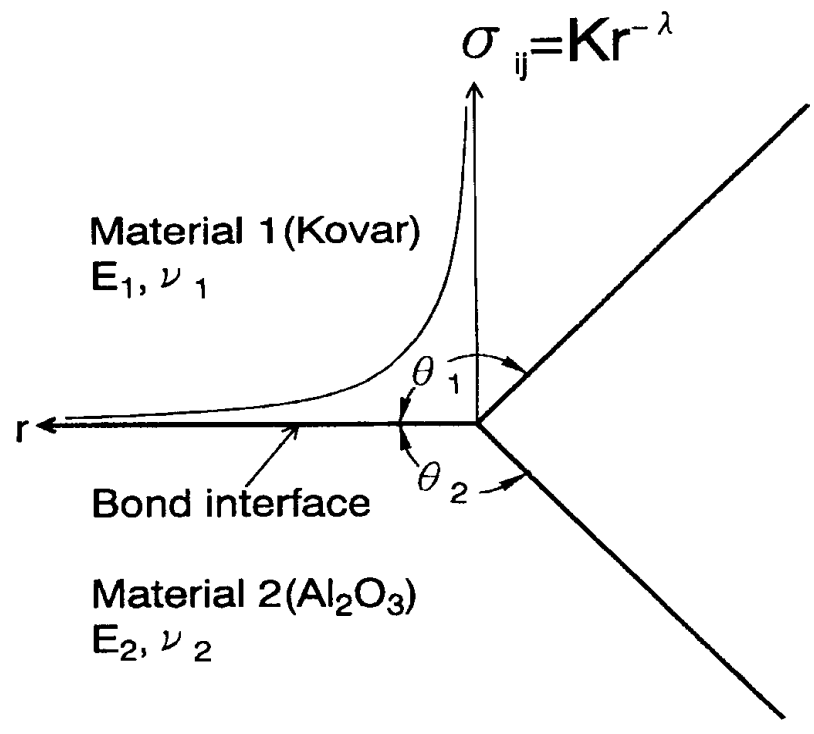

Fig. 3 Schematic drawing of dissimilar material joint.

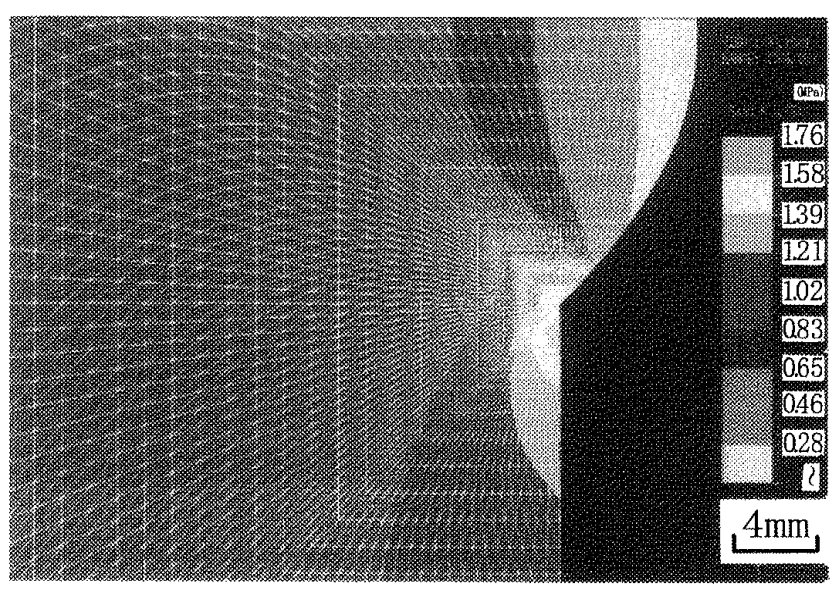

Fig.4 Distribution of the largest principal stress in the optimum shape for plain strain model of dissimilar material joint without interlayer.

図 4 は, 中間層のない平面ひずみモデルで，接合 部の形状最適化処理を行った結果を, 最大主応力分 布図として示したものである。ただし，図は初期基 本形状の図 2 (a)のA部にあたる部分を主に示してい る.また, 図 5 はこの最適化過程において, モデル の体積減少がどのように進むかを比で示した図であ る.図中には, 各段階で, 要素中もっとも大きい最 大主応力が初期モデルに対してどう変化しているか も, 比の形で示してある.これをみると, 形状最適 化の最初の段階での体積減少効果には著しいものが あるが, ステップが進むにつれて, 体積の減少の度 合は緩やかになることがわかる，また，最大主応力 值も最適化の進行にともない，途中一時的に增加す る場合がみられるものの, 基本的には減少の方向に 


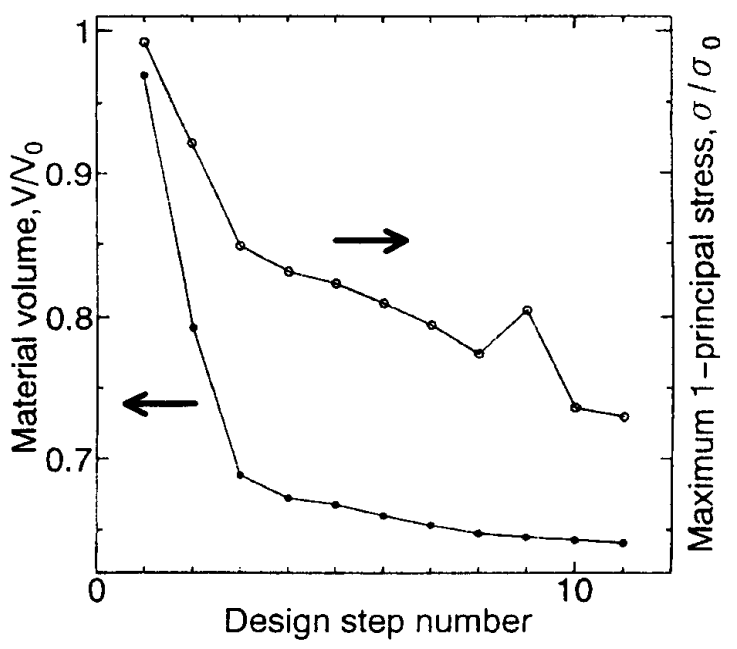

Fig.5 Variation of material volume and maximum principal stress of the plain strain model of dissimilar material joint without interlayer.

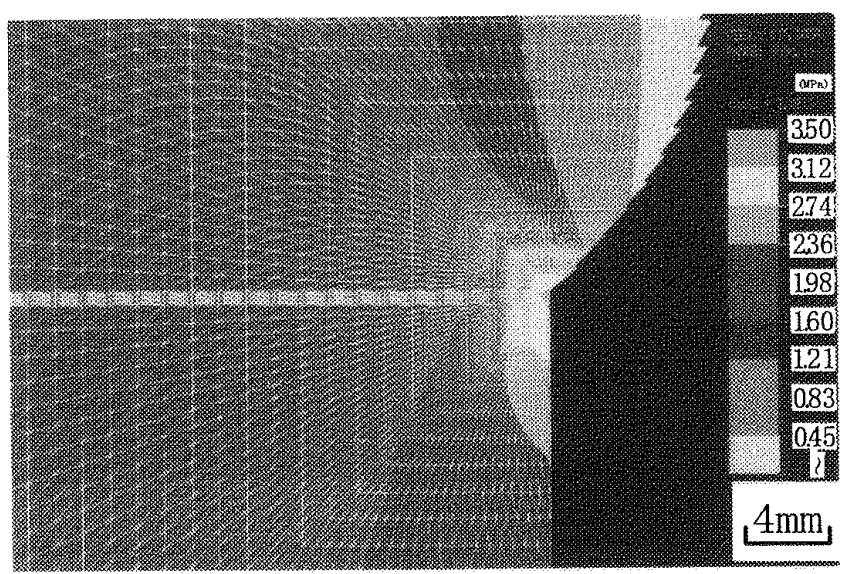

Fig. 7 Distribution of the largest principal stress in the optimum shape for axisymmetric model of dissimilar material joint with interlayer.

向かうことがわかる，すなわち，形状最適化により， 最大主応力值を下げることが可能であることを示し ている.

図 6 は, 中間層のない平面ひずみモデルの形状最 適化で, 界面での主応力の分布が, 初期モデルから どのように変化したかを示した図である。形状最適 化により, 応力の分布状態が変化して, 自由縁近傍 での主応力の増加が抑制されるようになることが認 められる。これは，この形状最適化には，自由縁の 特異応力を減少させる効果があることを示している。

図 7 は, 中間層のある軸対称モテルで, 最適化の 結果得られた形状を，その最大主応力分布図として 示したものである．ただし，図は初期基本形状の図 2 (b)の B 部にあたる部分を主に示している. 図 8 は, 中間層のある軸対称モデルの場合の界面での主応力

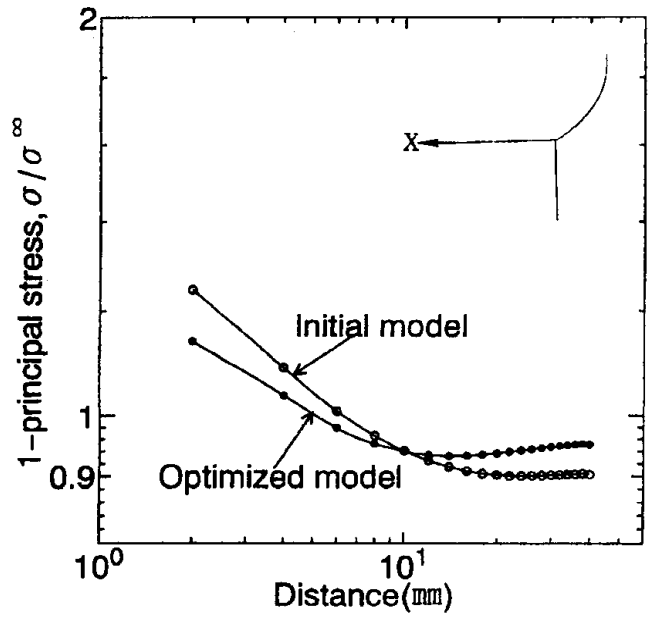

Fig.6 Variation of principal stress at interface before and after shape optimization for the plain strain model of dissimilar material joint without interlayer.

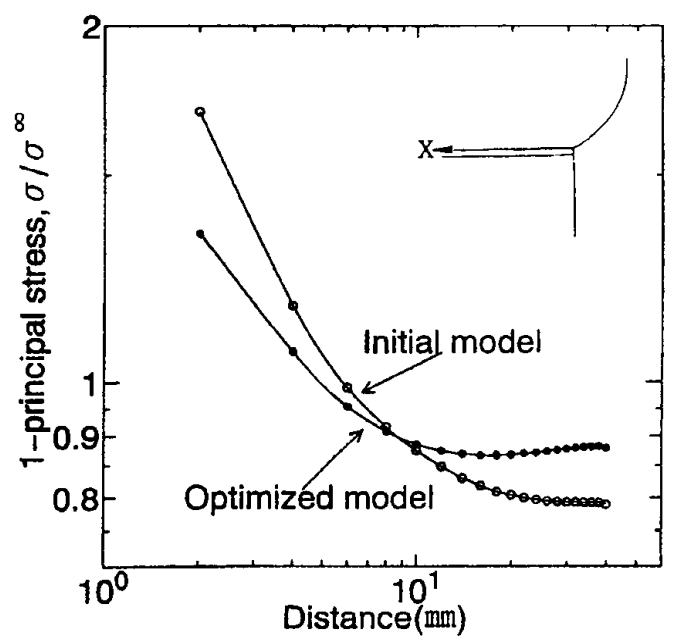

Fig.8 Variation of principal stress at interface before and after shape optimization for the axisymmetric model of dissimilar material joint with interlayer.

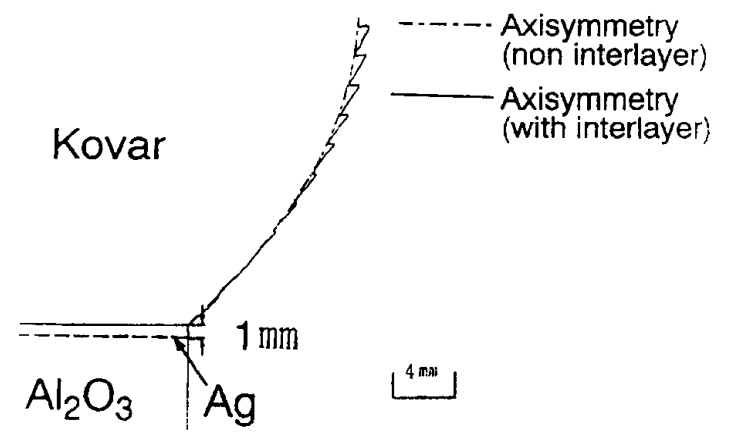

Fig.9 Optimum shape of the axisymmetric models of dissimilar material joint with and without interlayer. 
の分布の変化を示している，特簧忍力の減少が中間 層が存在する接合体でも認められることがわかる。

図 9 は，軸対称モデルにおいて，中間層がある場 合とない場合で，最適化後の形状がどうなるかを示 した図であるが，得られる形状は雨者でほと儿ど差 がないことがわかる．他の材料の組み合わせではど うなるかという点についての詳紐な検討は行ってい ないが，最適化の観点からみると，界面に中間屏が 存在した場合にその形状をどうするかという問題に ついては，基本的には中間層のない場合と同様に对 処できる可能性があることを示哱している。

図 10 は，中間層のない場合で，平面ひずみもしく は平面応力モデルで，最適化により得られる形状を， 既に述へたた久保・大路の理論的考察ににより得られ る形状と比較したのもである。また，図には軸対称 モデルに打ける本解析結果も小してある。これをみ ると、平面ひずみ，半面応力，軸対称モデルの違い による，最適化形状の違いはほとんどみられないこ とがわかる，また，平面ひずみ，平面応力モデルで， 久保・大路の理論解(2)之の比較をすると, 最適化処 理により得られる形状の開き觕 $\theta_{1}$ は理論解に近く， これは最適化に処理により,接合体の自由縁形状が, 特異性消失の条件を满たす力问に近ついて変化して いくことを示唆している，以ト:の上うに，巽材接合 体の形状の設計については，有限要素最適化 $\mathrm{CAE} シ$ ステムを利用することにより，その自由縁特異応力 を減少させた形状設計が可能であることが明らかと なり，その実用性と将来への発展性が認められる。

\section{4. 結}

異材接合体の自由縁特異忍力を減少させた形状設 計を, 有限要素最適化 CAEシステムを利用して試み た.セラミックス・金属接合体として, $\mathrm{Al}_{2} \mathrm{O}_{3} \cdot \mathrm{Kovar}$ 接合体をモデ化し，中間層として Ag が存在する 場合も含めて，形状最燠化を行った，最適化により 得られる形状は，中間層が存在しても，基本的には 中間層がない場合と同様になることが明らかとなっ た、また、いずれの場合でも，形状最適化により， 応力の分布状態が変化して，自由縁近傍での主㚇力 の增加が抑制されることが明らかとなった。これは， 形状最適化により，自由縁の特異応力を減少させる ことが可能であることを示している. また，最適化 処理により，接合体の自由秝形状が，理論的考察を もとにした特異性消失の条件を満たす方向に近つく 傾向があることが明らかとなった，以上のように，

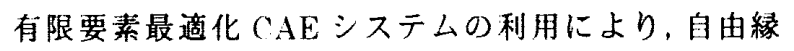
特異応力を減少させる形状設計が可能であることが

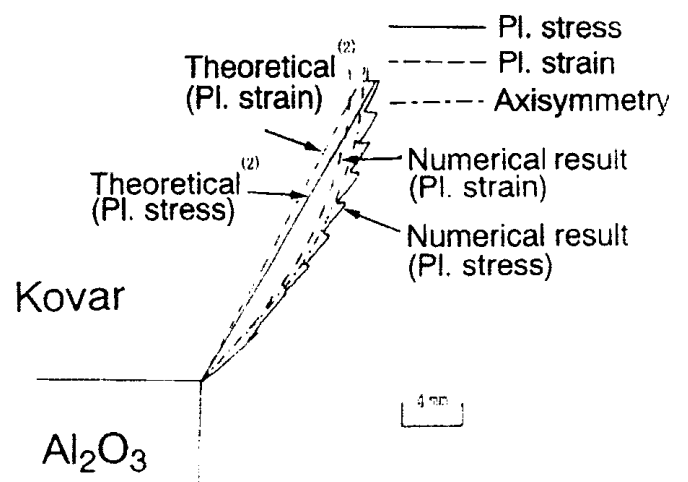

Fig.10 Optimum shape of the plain strain and plain stress models of dissimilar material joint without interlayer. The shape derived from theoretical calculation is also represented.

示され，その実用性と将来への発展性が誌められる。 本研究を行うに当たり，当時の大阪大学学梳，下 入佐公光君の協力を得た。ここに謝意を表する。

\section{文}

（1）結城, 界面の力学, (1993), 培風館, 第 1,2 章.

(2) 久保 ·大路, 機論, 57-535，A (1991), 632636.

(3) Murakawa, H. and UEDA. Y.. Transactions of JWRI, 19-2 (1990), $231-239$.

(4) 上田・村川，溶接学会誌，60-7 (1991).587-591

(5) 日本機械学会編, 構造・材料の最適設計, (1989), 技報堂出版，第 7 章.

(6) 山川，最適化デザイン. (1993), 培風館, 第 8 章.

(7) Engineering Mechanics Research Corporation 著，(株)ゼクセルインテリジェンス 訳, NISA IIユーザーズマニュアル (1992), ゼクセルイン テリジェンス.

(8) Engineering Mechanics Research Corporation. SHAPE User's Manual, Version91.0 (1991).

(9) Atrek. E., Agarwal. B., Shape Optimization of Structure Design, Paper entered in the 1990 IBM Supercomputing Competition. January (1991).

(10) 酒井 - 和内 - 渡辺, 日本機珹学会第5回計算力 学講演会講演論文集, No.920.92 (1992), 297 298.

(11) 村田 - 向井, 機論, 58 556, A (1992), 169174 . 